\title{
Self-Awareness: Behavior Analysis and Neuroscience
}

\author{
Travis Thompson \\ University of Minnesota School of Medicine and \\ Minnesota Early Autism Project
}

\begin{abstract}
Self-awareness is a specific type of autoclitic discriminative behavior and inferential generalization to similar performances exhibited by other people. Brain imaging findings take on special importance within behavior analysis when they indicate that dysfunctions in these areas are related to differential effects of our interventions, with some acquiring substantially typical self-awareness skills and others failing to do so. It appears that those individuals whose brain dysfunctions are limited to these areas, and are not part of more generalized brain abnormalities, are amenable to substantial acquisition of those most basic of human skills called self-awareness, whereas individuals with more generalized brain dysfunction are not so disposed. Through a combination of less or more effective teaching contingencies during childhood, and degrees of dysfunction of those brain structures, some children grow up lacking self-reflective abilities and self-insight, whereas others are extraordinarily astute at those capacities. Among children with autism spectrum disorders who lack those skills due to abnormal brain development, approximately half of them can acquire those skills, at least to some degree through the use of effective, intensive, early behavior therapy methods.
\end{abstract}

Key words: self-awareness, autoclitics, neuroplasticity

Historically, humankind has been ambivalent about the self. To be selfless is to be magnanimous, presumably a good thing, whereas a surfeit of self (i.e., being self-ish) refers to the converse, a less desirable trait. The self has been the frequent topic of literature, poetry, and visual arts. The development of self-portraiture depended on developing new technology. It was not until glass making had improved to the point that inexpensive smooth mirrors could be made that reflected an accurate image of the artist that self-portraits emerged in the mid-15th century with Van Eyck and Durer. From the very beginning, artists attempted to reveal more about themselves in self-portraits than their mere external appearance. Albrecht

This paper is based on a presentation as part of the symposium "Celebrating and Expanding our Scientific Foundations: State of the Science Addresses," May, 2008, at the annual meeting of the Association for Behavior Analysis International, Chicago. I thank Tim Hackenberg for his leadership in organizing the symposium and Max Hocutt for helpful discussions early in the formulation of this paper.

Address correspondence to the author at 2187 Ferris Lane, Roseville, Minnesota 55113 (e-mail: thomp199@umn.edu).
Durer created a Christ-like self-portrait that apparently was intended to convey his inner spirituality and Godgiven talent. The famous self-portrait of the English painter Joshua Reynolds of himself as visionary is another example of portraying a psychological trait through self-portraiture (LucieSmith \& Kelly, 1987).

With the ascendance of Watson's behaviorism, Boring (1950) famously proclaimed that psychology first lost its soul, then its mind, and finally its consciousness. Skinner's behavior analysis led many of us to believe it was finally safe to go into intellectual water, but then the cognitive revolution occurred, and dualism reemerged with a vengeance in psychology (Chomsky, 1959; Neisser, 1967). Rapidly emerging neuroscience technologies further opened the door to dualistic psychology. Brain imaging tools have lent undeserved scientific legitimacy to ill-conceived, mentalistic notions within psychology (Frith, 2007; Gazzaniga, 1991).

\section{COGNITIVE NEUROSCIENCE AND MENTALISM REDUX}

A major relapse to dualistic mentalism was triggered three decades 
ago, when, in their Behavioral and Brain Sciences article, Premack and Woodruff (1978) wondered whether their chimpanzee Sarah "had a theory of mind." They asked whether Sarah reflected on her own thoughts and feelings, and was aware that other organisms, mainly people, also had thoughts, feelings and motives like her own. Their provocative question triggered an enormous outpouring of mischief that continues today to masquerade as serious scientific discourse. Nowhere is this preoccupation more evident than in the field of autism research and theoretical writing, provoked by Baron-Cohen, Leslie, and Frith's (1985) article that reported the results of the Sally and Ann "false belief" test. What philosophers call "the problem of other minds" has so firmly taken hold of a great deal of developmental psychology, especially in the U.K., that many scientists have unabashedly adopted the metaphorical language of "mind-blindness" and "mindreading," as though those terms referred to actual physical phenomena. But not all developmental psychologists in the U.K. have adopted this position. In a paper titled "Getting Over 'the Problem of Other Minds': Communication in Context," Costall and Leudar (2007) wrote, "Theory of Mind' is now ... not so much a theory, more a way of life" (p. 290). Theory of mind and self-awareness are intertwined, raising philosophical and empirical questions that I would like to explore.

\section{PHILOSOPHICAL ISSUES}

Not a theory. In the first instance, Theory of Mind, the capitalized version, is not a theory of mind, lower case. It is not a theory at all. We do not really expect chimps or children with autism to possess the ability to formulate formal theories regarding other people's mental machinations. Theory of mind is actually a statement about a pre- sumed ability, or lack thereof, among very young children and people with autism spectrum disorders. In this sense, theory of mind is more akin to the ability of most Fijian children to sing confidently, without self-consciousness, in accurate pitch and rhythm, and at times loudly, with great enthusiasm. A Fijian child who is unable to sing is an aberration (Russell, 2001). No theory is involved in Fijian singing whatsoever; this ability is likely due to genetic makeup and early musical experience. Although theory of mind is cloaked in the language of cognitive neuroscience, this amounts to resurrection of a very old issue that has preoccupied philosophers since Descartes cleaved the mind from the body. It is a way of reintroducing the dualistic concept of consciousness or self, by way of the back door, into legitimate empirical discourse.

Category mistake. A second related philosophical issue involves Ryle's (1949) category mistake. Ryle pointed out that it was not appropriate to analyze the relation between mind and body as if they were terms of the same logical category, which they are not. Baron-Cohen et al. (1985) asked whether children with autism "have" a theory of mind, much as one might ask whether they have chicken pox. But unlike chicken pox, theory of mind is a mental rather than a material concept. It belongs in a nonmaterial concept sphere. Instead of theory of mind interacting with the corporeal body via the pineal gland as Descartes suggested, the amygdala has been proposed as the transducer of physical events into mental events (Baron-Cohen et al., 2000).

An enigmatic riddle? Perhaps theory of mind is not amenable to scientific inquiry, that is, whether an individual with autism exhibits selfawareness, and by extension, awareness that other people have selves that are also aware. Theory of mind may be an enigma in the tradition of the Mad Hatter's riddle in Alice in 
Wonderland (Carroll, 1865/1976), "Why is a raven like a writing-desk?" When Alice gave up and asked the Hatter for the answer, he replied, "I haven't the slightest idea" - a response similar to my initial reaction when someone asks me about theory of mind. But Wittgenstein (1961) reminded us, "The riddle does not exist. If a question can be put at all, then it can also be answered"' (p. 6.5), a view that I have come to share. So perhaps the difficulty we are having stems from asking the question improperly. I believe there is a question to be answered if we ask it the right way. It would probably help if we could agree on what we mean by the word self.

\section{WHAT IS SELF?}

Self as a mental entity does not exist. David Hume, the 18th century Scottish philosopher, said that when he looked into himself, all he could find was the thoughts and feelings, no self. He thereby declared the self to be a philosophical fiction (Hume, (1739/2006). In Philosophical Foundations of Neuroscience, Bennett and Hacker (2003) state,

The notion of "self" is an aberration. There is no such thing as "self" ... the confusion stems from inserting a space in the reflexive pronoun "myself," "yourself," "ourselves" to yield the aberrant expressions "my self," "your self" and "our selves." Having opened up an illicit space, we then fall into it. (p. 331)

Inner speech and self-awareness. Morin (2007) has suggested that self-awareness relies to a large extent on inner speech, by which he means "the activity of silently talking to oneself" (p. 117). He goes on to argue, "one becomes self-aware when one engages in self-talk (higher order thought) about one's current mental states and personal characteristics" (p. 117). His hypothesis is similar, in some respects, to Skinner's analysis of self-editing in Verbal Behavior (1957, p. 369). He suggests that inner speech emulates the role of the audience or listener in providing social consequences that shape and create self-awareness.

What are the discriminative stimuli that occasion the responses "myself" or "yourself"? In Beyond Freedom and Dignity (1971), Skinner wrote,

A self is a repertoire of behavior appropriate to a given set of contingencies. ... A person may report, "I'm not myself today," or "I couldn't have done what you said I did, because that's not like me." The identity conferred upon a self arises from the contingencies responsible for the behavior. ... The picture which emerges from a scientific analysis is not a body with a person inside, but of a body which is a person in the sense that it displays a complex repertoire of behavior. (p. 199)

\section{AUTOCLITIC SELF-AWARENESS}

Inner speech per se may not be necessary to self-awareness, but some form of discriminative responding based on one's own verbal behavior is required. One can respond differentially to one's own verbal behavior without those responses taking the form of speech, although such discriminative responses are often speech. In his chapter on autoclitics in Verbal Behavior (1957), Skinner wrote,

Part of the behavior of an organism becomes in turn one of the variables controlling another part. There are at least two systems of responses, one based on the other. The upper level can only be understood in terms of its relations to the lower. The notion of an inner self is an effort to represent the fact that when behavior is compounded in this way, the upper system seems to guide or alter the lower [italics added]. (p. 313)

But the controlling system is also behavior. The speaker may "know" what he or she is saying in the sense in which he or she "knows" any part or feature of the environment. Some of his or her behavior (the known) serves as a variable in control of other parts (knowing).

When we say a person is selfaware, we mean that he or she 
responds discriminatively to his or her own externally observable behavior (e.g., looking in a mirror) or products of the behavior (e.g., the ball flying through the air that he or she just struck with a racket), much as he or she discriminates others' observable actions. To say, for example, "I'm reasonably good at water color painting," could be part of self-awareness. But we also mean that the individual responds to his or her own dispositions or tendencies to behave as well as externally verifiable actions or products of our actions, what Skinner called higher order autoclitics. To say "I'm eager to see the exhibit at the Art Institute" is to respond discriminatively to the state of strength of a disposition to behave. To say one is goal oriented identifies a class of controlling reinforcers for one's own behavior. The ability to tact variables that often exercise control over one's behavior is an important part of what we mean by being self-aware.

\section{INFERENTIAL GENERALIZATION}

The tendency to respond discriminatively to others' dispositions and motives is presumably an instance of inferential generalization based on experience with one's own behavior and dispositions. In the Sally and Ann false-belief test (Baron-Cohen et al., 1985), experimenters show children a simple scenario, in which a doll named Sally puts a marble in her basket and then leaves the scene. While Sally is away and cannot watch, a second doll, Ann, takes the marble out of Sally's basket and puts it into her box. Sally then returns and the children are asked where they think Sally will look for her marble. Children are said to pass the test if they say that Sally will look inside her basket before realizing that her marble is not there. Inferential generalization, based on observing their own and others' behavior, does not occur in typical children under approxi- mately the age of 3 or 4 years. Similarly, most children with autism will answer "Ann's box," seemingly unaware that Sally does not know her marble has been moved.

\section{ADDITIONAL EMPIRICAL ISSUES}

Introspection and brain imaging. What are we to make of the fact that people with autism spectrum disorders often fail to exhibit these types of self- and other-awareness skills, though they have presumably been exposed to reinforcement contingencies similar to other members of their families and community? An introspective approach attempts to make sense of this discrepancy by calling on the participant to answer, "What do you think she thinks?" But that does not help to explain the phenomenon; it merely describes the same events using other words. To state that the child must be capable of higher order representation is reification and explains nothing either. When a researcher tells us the left inferior temporal sulcus is more likely to be activated when one is engaged in self-evaluative inner speech (Morin, 2005, p. 126), although that may be right, that does not actually explain self-evaluation. It would be like saying increased activity of $\mathrm{V} 1$ in the visual cortex explains performance of a red-green visual discrimination, which it does not. It may be a requirement for a red-green discrimination but it is not the same thing as a red-green discrimination.

Necessary conditions for such performances to be demonstrated. Sidman (1960) suggested that explaining a phenomenon involves determining the conditions under which that phenomenon occurred or did not occur (p. 17), taking a page from Bernard's Experimental Medicine (1865/1949, p. 66). In that spirit, let's suppose we are working with a 4.5year-old child with a diagnosis of autistic disorder, who has consider- 
able receptive vocabulary but limited functional pragmatic language. $\mathrm{He}$ engages in some compulsive rituals and occasionally exhibits behavioral outbursts when expected routines are altered. How would we go about determining the conditions necessary to establish behavior we take as indicative of self-awareness and awareness of other selves?

1. Teaching observable aspects of himself versus another person (motor imitation, receptive pointing to his own body parts, receptive pointing to another person's body parts, teaching him to name his actions, teaching him to name others' actions).

2. Teaching identification of common self-feeling states (e.g., hungry, tired, happy, sad, angry) and associated external signs (e.g., facial expression, body posture).

3. Teaching identification of common feeling states of others (e.g., hungry, tired, happy, sad, angry) and associated external signs (e.g., facial expression, body posture).

4. Teaching generalization of (3) across various people.

5. Teaching causal sequences, beginning with simple two-step sequences and extending to multistep scenarios.

6. Teaching the kinds of events (i.e., operations) that are associated with feeling states building on previous causal sequence training (first self, then other; e.g., haven't eaten anything for a long time, staying up late, receive a present, dropped ice cream cone, another child shoves you).

Having completed this series of skill-building exercises, the youngster displays skills similar to those other typical children display when called on to indicate their understanding of others' emotions or motives. Additional teaching may be required to enable many children with autism spectrum disorders to correctly respond to deceitful behavior; however, the process would be similar. The fact that many children with autism are as able as typical controls to judge culpability based on vignettes in which actions were either deliberate or accidental and caused injury to a person or damage to property suggests that these are teachable skills to children with autism spectrum disorders (Grant, Boucher, Riggs, \& Grayson, 2005). In this study, these children were able to state the basis of motive and to judge injury to persons as more culpable than damage to property.

Brain prerequisites to self-aware behavior. There are likely additional necessary conditions for self-awareness to emerge, as I recently suggested (Thompson, 2005). Although questions have been raised about the reliability of brain imaging findings (Uttal, 2004), there is a high degree of agreement about dysfunction in several brain areas during functional magnetic resonance imaging in many higher functioning youth and young adults with autism spectrum disorders, as well as anatomical differences in some cases:

Amygdala: Baron-Cohen et al. (2000); Dalton, Nacewicz, Alexander, and Davidson (2006); Juranek et al. (2006); Kleinhans et al. (2008).

Fusiform gyrus: Schultz et al. (2000); van Kooten et al. (2008).

Prefrontal cortex: Gilbert, Bird, Brindley, Frith, and Burgess (2008); Hardan et al. (2006).

Cingulate cortex: Chiu et al. (2008); Thakkar et al. (2008).

Broca's and Wernicke's areas: Bigler et al. (2007); De Fosse et al. (2004).

Mirror neurons (superior parietal cortex): Cattaneo et al. (2007); Dapretto et al. (2006); Oberman et al. (2005).

Research to date has been insufficient to determine the percentage of children with ASDs who are able to acquire self-awareness skills under well-specified conditions. Repertoires that are prerequisites to the foregoing sequences have been acquired by about half of the children with autism 
spectrum disorders who have been involved in intensive early-intervention programs (Eikeseth, in press; Lovaas, 1987; Remington et al., 2007; Sallows \& Graupner, 2005). That suggests that for those children who are able to acquire such prerequisite skills, there must be sufficient residual distribution of neurons with dendritic proliferation and axons in some or all of the above dysfunctional brain areas, through reinforced practice of those skills, that are capable of forming synapses, to compensate for initial deficits.

The tenability of the hypothesis that reinforced practice-dependent synaptogenesis is the basis of acquiring self-awareness skills among children with autism (or very young typical children) emanates from laboratory animal studies. Randy Nudo, Michael Merznich, Jeff Kleim, and colleagues have conducted a series of studies with rats and monkeys that clearly demonstrate that dendritic spine growth and synaptogenesis occur in motor cortex as a consequence of reinforced practice, and that when reinforcement ceases, the number of such newly formed synapses regresses (Kleim et al., 2002; Kleim, Barbay, \& Nudo, 1998; Nudo, Milliken, Jenkins, \& Merzenich, 1996). I have elsewhere described these changes as conjoint mediating events (not effector events) (Thompson, 2007).

A recent study (Morrow et al., 2008) by a consortium led by Christopher Walsh of Boston Children's Hospital reported deletion of several genes among children with autism, whose level of expression changes in response to neuronal activity (i.e., experience), that are involved in synaptic changes that underlie learning. They hypothesize the reason that intensive early intervention is effective among many children with autism is that it promotes neuronal activity in these cells that underlie synapse formation. This would be consistent with the foregoing analy- sis, as well as my previous proposals (Thompson, 2005, 2007).

There is no "self-awareness" brain center. The fact that these structures appear to be dysfunctional among individuals with autism who lack selfawareness (as previously operationally defined) does not prove that those dysfunctions are causally related to lack of self-awareness, but strongly suggests that it is likely. It implies that in addition to appropriate exposure to systematic experiences through differential reinforcement and stimulus control procedures, certain brain prerequisites very likely are necessary as well. But those brain prerequisites are no more the locus of self-awareness than the pineal gland was the seat of the soul, as Descartes suggested. That type of assumption is a regrettably common error among many in cognitive neuroscience. Ted Williams' or Ty Cobb's primary and supplementary motor cortices were very likely activated when they swung their baseball bats, but this does not mean that those cortical structures were their brains' baseball-batting centers.

\section{CONCLUDING THOUGHTS}

Self-awareness is a specific type of autoclitic discriminative behavior and inferential generalization to similar performances exhibited by other people.

To those of us in the field of behavior analysis, brain imaging data take on special importance when they indicate dysfunctions in those areas related to differential effects of our interventions, with some acquiring substantially typical self-awareness skills and others failing to do so. It appears that those individuals whose brain dysfunctions are limited to these areas, and are not part of more generalized brain abnormalities, are amenable to substantial acquisition of those most basic of human skills called self-awareness, whereas individuals with more generalized brain dysfunction are not so disposed. 
Within the general population there are likely degrees of typical and atypical functional combinations of those brain structures that make it easier or more difficult to acquire self-awareness skills through exposure to the usual contingencies of child rearing. Through a combination of less or more effective therapy or teaching contingencies during childhood, and degrees of dysfunction of those brain structures, some children grow up lacking self-reflective abilities and self-insight, and others are extraordinarily astute at those capacities.

Among children with autism spectrum disorders who lack those skills due to abnormal brain development, approximately half of them can acquire those skills, at least to some degree, through the use of effective, intensive, early behavior therapy methods.

\section{REFERENCES}

Baron-Cohen, S., Leslie, A. M., \& Frith, U. (1985). Does the autistic child have a "theory of mind"? Cognition, 21, 37-46.

Baron-Cohen, S., Ring, H. A., Bullmore, E. T., Wheelwright, S., Ashwin, C., \& Williams, S. C. (2000). The amygdala theory of autism. Neuroscience and Biobehavioral Reviews, 24, 355-364.

Bennett, M. R., \& Hacker, P. M. S. (2003). Philosophical foundations of neuroscience. Malden, MA: Blackwell Publishing.

Bernard, C. (1949). An introduction to the study of experimental medicine $(\mathrm{H}$. C. Greene, Trans.). New York: Henry Schuman. (Original work published 1865)

Bigler, E. D., Mortensen, S., Neeley, E. S., Ozonoff, S., Krasny, L., Johnson, M., et al. (2007). Superior temporal gyrus, language function, and autism. Developmental Neuropsychology, 31, 217-238.

Boring, E. G. (1950). History of experimental psychology (2nd ed.). New York: AppletonCentury-Crofts.

Carroll, L. (1976). The annotated Alice: Alice's adventures in wonderland and through the looking glass. New York: Bramhall House. (Original work published 1865)

Cattaneo, L., Fabbri-Destro, M., Boria, S., Pieraccini, C., Monti, A., Cossu, G., et al. (2007). Impairment of actions chains in autism and its possible role in intention understanding. Proceedings of the National
Academy of Sciences USA, 104, 1782517830.

Chiu, P. H., Kavali, M. A., Kishida, K. T., Tomlin, D., Klinger, L. G., Klinger, M. R., et al. (2008). Self-responses along cingulate cortex reveal quantitative neural phenotype for high-functioning autism. Neuron, 57, 463-473.

Chomsky, N. (1959). A review of B. F. Skinner's Verbal Behavior. Language, 35, 26-58.

Costall, A., \& Leudar, I. (2007). Getting over "the problem of other minds": Communication in context. Infant Behavior \& Development, 30, 289-295.

Dalton, K. M., Nacewicz, B. M., Alexander, A., \& Davidson, R. J. (2006). Gaze-fixation, brain activation, and amygdala volume in unaffected siblings of individuals with autism. Biological Psychiatry, 61, 512-520.

Dapretto, M., Davies, M. S., Pfeifer, J. H., Scott, A. A., Sigman, M., Bookheimer, S. Y., et al. (2006). Understanding emotions in others: Mirror neuron dysfunction in children with autism spectrum disorders. $\mathrm{Na}$ ture Neuroscience, 9, 28-30.

De Fosse, L., Hodge, S. M., Makris, N., Kennedy, D. N., Caviness, V. S., Jr., McGrath, L., et al. (2004). Languageassociation cortex asymmetry in autism and specific language impairment. Annals of Neurology, 56(6), 755-756.

Eikeseth, S. (in press). Outcome of comprehensive psycho-educational interventions for young children with autism. Research in Developmental Disabilities.

Frith, C. (2007). Making up the mind: How the brain creates our mental world. Malden, MA: Blackwell.

Gazzaniga, M. S. (1991). Cognitive neuroscience: A reader. Malden, MA: Wiley-Blackwell.

Gilbert, S. J., Bird, G., Brindley, R., Frith, C. D., \& Burgess, P. W. (2008). Atypical recruitment of medial prefrontal cortex in autism spectrum disorders: An fMRI study of two executive function tasks. Neuropsychologia, 45, 2281-2291.

Grant, C. M., Boucher, J., Riggs, K. J., \& Grayson, A. (2005). Moral understanding in children with autism. Autism, 9, 317-331.

Hardan, A. Y., Girgis, R. R., Lacerda, A. L., Yorbik, O., Kilpatrick, M., Keshavan, M. S., et al. (2006). Magnetic resonance imaging study of the orbitofrontal cortex in autism. Journal of Child Neurology, 21, 866-871.

Hume, D. (2006). Treatise on human nature. I. iv. 6. Personal identity. Retrieved July 12, 2008, from http://ebooks.adelaide.edu.au/h/ hume/david/h92t/B1.4.6.html

Juranek, J., Filipek, P. A., Berenji, G. R., Modahl, C., Osann, K., \& Spence, M. A. (2006). Association between amygdala volume and anxiety level: Magnetic resonance 
imaging (MRI) study in autistic children. Journal of Child Neurology, 21, 1051-1058.

Kleim, J. A., Barbay, S., Cooper, N. R., Hogg, T. M., Reidel, C. N., Remple, M. S., et al. (2002). Motor learning-dependent synaptogenesis is localized to functionally reorganized motor cortex. Neurobiology of Learning and Memory, 77, 63-77.

Kleim, J. A., Barbay, S., \& Nudo, R. J. (1998). Functional reorganization of the rat motor cortex following motor skill learning. Journal of Neurophysiology, 80, 3321-3325.

Kleinhans, N. M., Richards, T., Sterling, L., Stegbaquer, K. C., Mahurin, R., Johnson, L. C., et al. (2008). Abnormal functional connectivity in autism spectrum disorders during face processing. Brain, 131, $1000-1012$.

Lovaas, O. I. (1987). Behavioral treatment and normal educational and intellectual functioning in young autistic children. Journal of Consulting and Clinical Psychology, 55, 3-9.

Lucie-Smith, E., \& Kelly, S. (1987). History of self-portraits, excerpted from Sean Kelly, The self portrait: A modern view. London: Sarema Press. Retrieved July 12, 2008, from http://userpages.umbc.edu/ ivy/selfportrait/ back.html

Morin, A. (2005). Possible links between selfawareness and inner speech. Journal of Consciousness Studies, 12, 115-134.

Morrow, E. M., Yoo, S. Y., Flavell, S. W., Kim, T. K., Lin, Y., Hill, R. S., et al. (2008). Identifying autism loci and genes by tracing recent shared ancestry. Science, 321, 218223.

Neisser, U. (1967). Cognitive psychology. Englewood Cliffs, NJ: Prentice Hall.

Nudo, R. J., Milliken, G. W., Jenkins, W. M., \& Merzenich, M. M. (1996). Use-dependent alterations of movement representations in primary motor cortex of adult squirrel monkeys. Journal of Neuroscience, 16, 785-807.

Oberman, L. M., Hubbard, E. M., McCleery, J. P., Alschuler, E. L., Ramachandran, V. S., \& Pineda, J. A. (2005). EEG evidence for mirror neuron dysfunction in autism spectrum disorders. Brain Research, 24, 190-198.

Premack, D., \& Woodruff, G. (1978). Does the chimpanzee have a theory of mind? The Behavioral and Brain Sciences, 1, 515-526.

Remington, B., Hastings, R. P., Kovshoff, H., Espinosa, F., Jahr, E., Brown, T., et al. (2007). Early intensive behavioral intervention: Outcomes for children with autism and their parents after two years. American Journal on Mental Retardation, 112, 418-438.

Russell, J. (2001). Born to sing: Fiji's "singing culture" and implications for music education in Canada. McGill Journal of Education. Retrieved July 13, 2008, from http://findarticles. com/p/articles/mi_qa3965/is_200110/ai_n8959362/ pg_1?tag=artBody;coll

Ryle, G. (1949). The concept of mind. Chicago: University of Chicago Press.

Sallows, G. O., \& Graupner, T. D. (2005). Intensive behavioral treatment for children with autism: Four-year outcome and predictors. American Journal for Mental Retardation, 110, 417-438.

Schultz, R. T., Gauthier, I., Klin, A., Fulbright, R. K., Anderson, A. W., Volkmar, F., et al. (2000). Abnormal ventral temporal cortical activity during face discrimination among individuals with autism and Asperger syndrome. Archives of General Psychiatry, 57, 331-340.

Sidman, M. (1960). Tactics of scientific research. New York: Basic Books.

Skinner, B. F. (1938). The behavior of organisms. New York: Appleton.

Skinner, B. F. (1957). Verbal behavior. New York: Appleton-Century-Crofts.

Skinner, B. F. (1971). Beyond freedom and dignity. New York: Knopf.

Thakkar, K. N., Polli, F. E., Joseph, R. M., Tuch, D. S., Hadjikhani, N., Barton, J. J., et al. (2008). Response monitoring, repetitive behaviour and anterior cingulate abnormalities in ASD. Brain, 131, 2464-2478.

Thompson, T. (2005). Paul E. Meehl and B. F. Skinner: Autitaxia, autitypy and autism. Behavior and Philosophy, 33, 101-131.

Thompson, T. (2007). Relations among functional systems in behavior analysis. Journal of the Experimental Analysis of Behavior, 87, $27-44$.

Uttal, W. R. (2004). Hypothetical high-level cognitive functions cannot be localized in the brain: Another argument for a revitalized behaviorism. The Behavior Analyst, 27, $1-6$.

van Kooten, I. A., Palmen, S. J., von Cappeln, P., Steinbusch, H. W., Korr, H., Heinsen, H., et al. (2008). Neurons in the fusiform gyrus are fewer and smaller in autism. Brain, 131, 987-999.

Wittgenstein, L. (1961). Tractatus logico-philosophicus (D. F. Pears \& B. F. McGuinness, Trans.). London: Routledge and Kegan Paul. 